\title{
Effect of stress relaxation on the evolution of residual stress during heat treatment of Ti-6Al-4V
}

\author{
W. Rae ${ }^{\mathrm{a}, *}$, S. Rahimi ${ }^{\mathrm{a}}$ \\ Advanced Forming Research Centre (AFRC), University of Strathclyde, 85 Inchinnan Drive, Glasgow, UK \\ *william.rae@strath.ac.uk
}

\begin{abstract}
Titanium alloys, such as Ti-6Al-4V, are extensively used in critical aerospace applications. Heat treatments are often conducted during forging processes to produce final microstructures which exhibit advantageous mechanical properties. However, high thermal gradients present during processing may lead to the generation of undesirable levels of residual stress. Stress relief can be achieved by conducting aging or annealing treatments at elevated temperatures, yet there is limited quantitative understanding of how holding temperature affects the evolution of residual stress. Stress relaxation testing was conducted between $500-750^{\circ} \mathrm{C}$ and the resulting response was modified to describe creep strain. This was implemented in DEFORM ${ }^{\mathrm{TM}}$ finite element analysis software to model the evolution of residual stress during solution treatment followed by aging between $500-750^{\circ} \mathrm{C}$, with comparison against solutions which did not consider creep strain. Stress relaxation phenomena was found to have an important impact on the reduction of residual stress and needs to be considered when carrying out thermo-mechanical processing at elevated temperatures.
\end{abstract}

\section{$\underline{\text { Introduction }}$}

Titanium alloys are often among selected materials for use in aerospace applications due to their favourable strength-to-weight ratio, as well as good temperature and corrosion resistance [1]. Of these, the dual-phase $\alpha+\beta$ alloy Ti- $6 \mathrm{Al}-4 \mathrm{~V}$ is the most widely produced [1]. This popularity is partially due to the vast array of microstructures which can be achieved by following a set of prescribed thermo-mechanical processes, producing tailored mechanical properties [1]. However, such processing can lead to misfits of a thermal, mechanical or metallurgical nature between different regions or phases within a workpiece; thus influencing the residual stress field [2].

Solution treatment may be employed post-deformation to obtain a bimodal microstructure with improved strength. This is conducted at high temperatures, in the $\alpha+\beta$ phase field $\left(>900^{\circ} \mathrm{C}\right)$, and may be followed by water quenching to minimise diffusion on cooling [1]. However, water quenching leads to the formation of brittle martensite $\left(\alpha^{\prime}\right)$, as well as high thermal gradients throughout the workpiece and in turn, high magnitudes of residual stress. These elevated levels of residual stress are associated with distortion during machining and a reduction in fatigue life which is undesirable [2]. Aging treatments are therefore often conducted at elevated temperatures to decompose any $\alpha^{\prime}$ into $\alpha$ - and $\beta$-phases and promote stress relaxation [1,3]. Whilst higher aging temperatures promote stress decay, this may lead to partial dissolution of the bimodal microstructure formed during solution treatment; adversely affecting strength $[1,4]$. This has led to the commercial application of various aging regimes with holding temperatures ranging from 500 to $750^{\circ} \mathrm{C}$ and above, and holding durations ranging from 0.5 to 24 hours $[1,5,6]$.

Previous finite element-based models for residual stress prediction in Ti-6Al-4V have predominantly focussed on additive manufacturing applications, where the timescales are relatively short and stress relaxation is often ignored or tuned to a stress-free temperature based on experimental data. Instantaneous stress free temperatures of $640^{\circ} \mathrm{C}$ and $800^{\circ} \mathrm{C}$ have been used by Denlinger et al. [7] and Bühr et al. [8], respectively. Yet such assumptions do not adequately describe stress decay for aging and annealing treatments. Despite a number of stress relaxation studies concerning Ti-6Al-4V at elevated temperature, there has been little attempt to apply the findings for optimisation of aging and annealing process parameters to manage residual stress [4,9-12].

Stress relaxation behaviour in Ti-6Al-4V is thought to be highly dependent on process history and significant variation in response has even been found between similar initial microstructures [5]. This has led to the recommendation that material specific stress relaxation data is gathered prior to application in finite element analysis (FEA) software.

The aim of the following work was to characterise the stress relaxation behaviour exhibited by Ti-6Al-4V over typical heat treatment temperatures of 500 to $750^{\circ} \mathrm{C}$ and determine the importance that this behaviour has on the evolution of residual stress through simulation in DEFORM ${ }^{\mathrm{TM}}$ FEA software.

\section{Materials \& Methods}


The material used in this study was derived from Ti-6Al-4V plate which had been subjected to hot rolling below $950^{\circ} \mathrm{C}$ to an approximate thickness of $38 \mathrm{~mm}$ and was followed by air cooling. Wire guided electrical discharge machining (EDM) was employed to cut miniaturised dogbone test specimens for mechanical testing and metallographic examination. Metallographic preparation was conducted by grinding and polishing to a mirror finish condition, followed by etching with Kroll's Reagent and examination using a Leica DM12000M Optical Microscope. The mechanical test specimens were extracted from a plane transverse to the rolling direction, with the observed microstructure of this orientation shown in Fig 1a and test specimen dimensions provided within Fig $1 \mathrm{~b}$.

An Instron ${ }^{\circledR}$ Electro-Thermal Mechanical Testing (ETMT) system was used for stress relaxation testing. Temperature was monitored at the centre of the test piece by means of a spot welded R-Type thermocouple and controlled by resistive heating. In order to minimise oxidation at elevated temperatures, an Argon atmosphere was introduced.

(a)

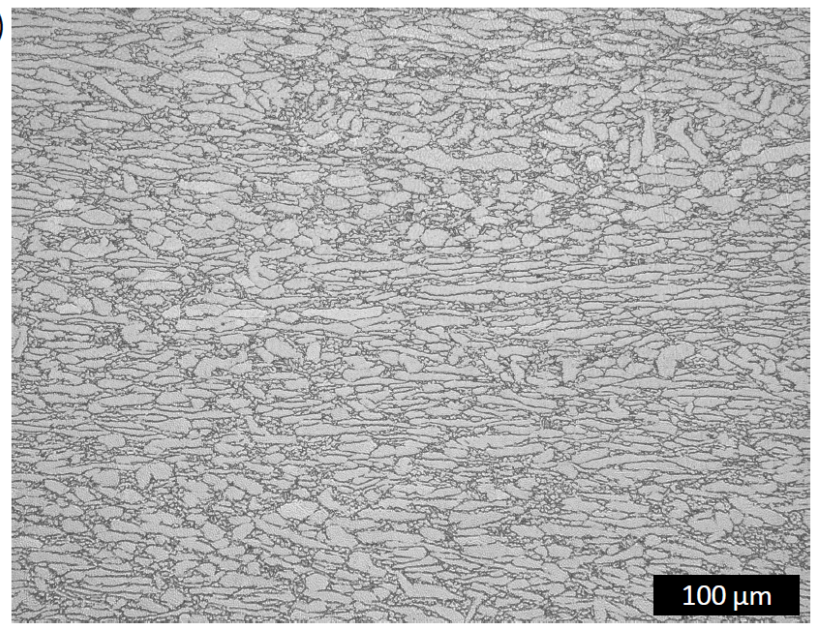

(b)
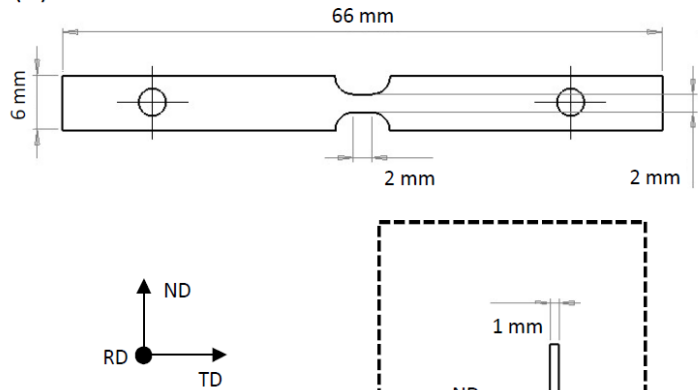

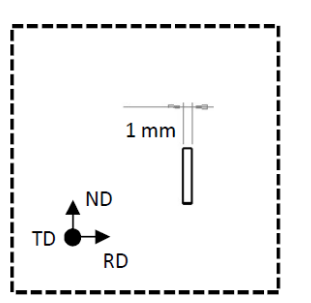

Fig 1: Optical micrograph of plate material in RD (a), and dimensions of ETMT test specimen (b).

Stress relaxation testing was conducted under isothermal conditions between $500-750^{\circ} \mathrm{C}$ at intervals of $50^{\circ} \mathrm{C}$, in accordance with ASTM E328-13. Each sample was initially heated to the test temperature at a rate of $5^{\circ} \mathrm{C} / \mathrm{s}$, followed by isothermal holding for 30 s. Tensile deformation was then conducted at a constant strain rate of $10^{-4} \mathrm{~s}^{-1}$ until a plastic strain of approximately $0.2 \%$ was achieved. The strain was then held constant for the remainder of the test under linear variable differential transformer (LVDT) control. Load relaxation was measured as a function of time under this constant strain regime for 1 hour, or until a constant stress was achieved. A schematic representation of a typical stress relaxation test is provided in Fig $2 \mathrm{a}$.

Stress relaxation data is most commonly presented in terms of stress versus creep rate and this conversion was conducted according to the methodology presented by Woodford [13]. As such the total strain rate after loading must be in equilibrium:

$$
\dot{\varepsilon}_{t}=\dot{\varepsilon}_{c}+\dot{\varepsilon}_{e}+\dot{\varepsilon}_{m}+\dot{\varepsilon}_{p}=0
$$

Where $\dot{\varepsilon}_{t}, \dot{\varepsilon}_{c}, \dot{\varepsilon}_{e}, \dot{\varepsilon}_{m}$ and $\dot{\varepsilon}_{p}$ are the total, creep, elastic, machine and plastic components of strain rate, respectively. Given that plastic strain is constant after loading, this reduces to:

$$
\dot{\varepsilon}_{c}=-\left(\dot{\varepsilon}_{e}+\dot{\varepsilon}_{m}\right)=-\left(\frac{\dot{\sigma}}{E}+\dot{\varepsilon}_{m}\right),
$$

Where $\dot{\sigma}$ is the rate of stress decay and $E$ is the elastic modulus of the material. This can be further simplified using an apparent elastic modulus, $E_{\text {App }}$; based on initial tensile response within the constant strain rate region, to account for machine stiffness:

$$
\dot{\varepsilon}_{c}=-\frac{\dot{\sigma}}{E_{\text {App }}} .
$$

In order to relate the observed stress relaxation behaviour to the evolution of heat treatment induced residual stress, a finite element model was developed using DEFORM ${ }^{\mathrm{TM}}$ software. A simple plate geometry of $250 \times 250 \times 38 \mathrm{~mm}^{3}$ was selected. An initial 1 hour solution treatment at $950^{\circ} \mathrm{C}$ followed by water quenching was modelled to introduce high magnitudes of residual stress. This was followed by a 1 hour aging operation which was simulated for temperatures from $500-750^{\circ} \mathrm{C}$, as shown in Fig $2 \mathrm{~b}$. Temperature dependent heat transfer coefficients (HTCs) were determined by inverse analysis of heat transfer during quenching and air cooling trials. Temperature dependent properties, including thermal expansion coefficient, Young's Modulus and strain-rate dependent flow stress were used. The stress versus creep rate data was then added to the pre-processor for calculation of the creep component of strain. Additional simulations were conducted without the creep model at $500^{\circ} \mathrm{C}$ and $750^{\circ} \mathrm{C}$ for comparison. Residual stress was calculated based on infinitesimal strain theory [5]. 

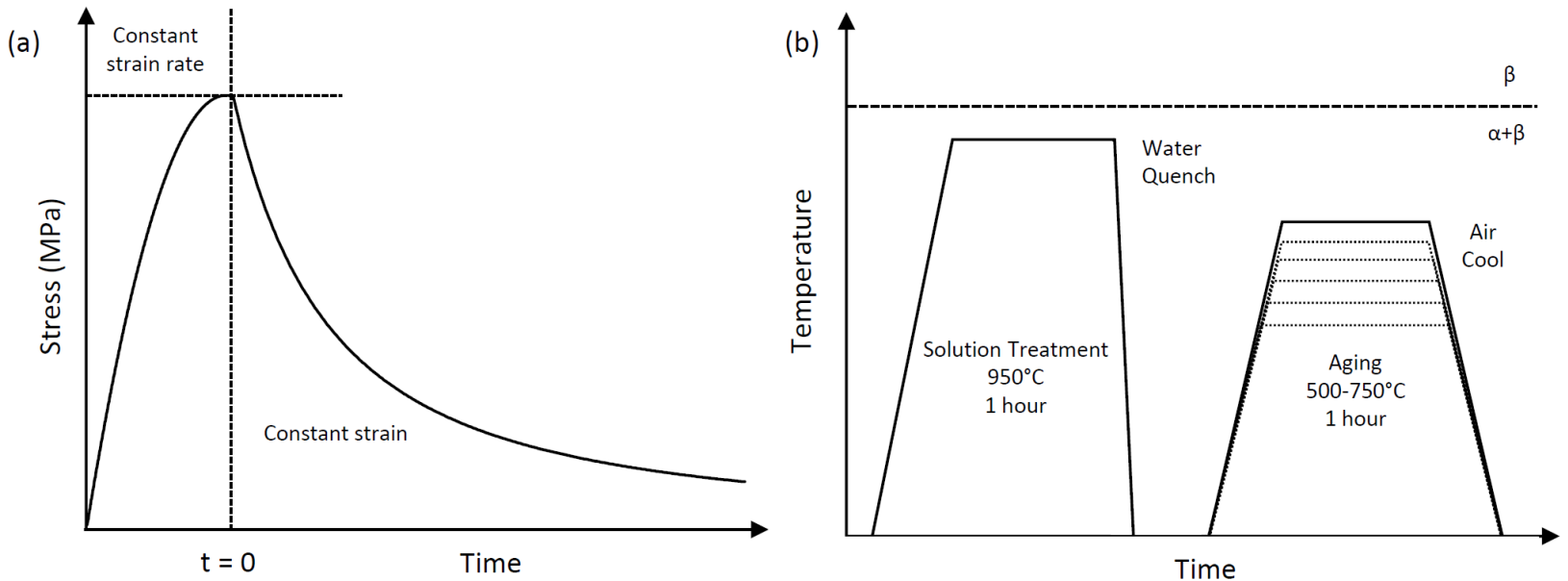

Fig 2: Schematic representation of isothermal stress relaxation test (a), and processing routes modelled in DEFORMTM (b).

\section{$\underline{\text { Results \& Discussion }}$}

The stress relaxation response for all investigated temperatures is presented in Fig 3a. This shows an initial stress roughly in accordance with the yield stress of Ti-6Al-4V under a strain rate of $10^{-4} \mathrm{~s}^{-1}$ at the respective test temperatures. The relative reduction in stress is seen to increase on increasing temperature, with a $50 \%$ reduction in stress noted after 1 hour at $500^{\circ} \mathrm{C}$, compared with a $95 \%$ reduction over 30 minutes at $750^{\circ} \mathrm{C}$. This change is seen to be most dramatic between 600 and $650^{\circ} \mathrm{C}$, with a $65 \%$ and $90 \%$ reduction after 1 hour, respectively. In addition, there appears to be almost complete relaxation after 30 minutes at both $700^{\circ} \mathrm{C}$ and $750^{\circ} \mathrm{C}$, both with a final stress of under $10 \mathrm{MPa}$. The converted stress versus creep rate data is provided in Fig $3 \mathrm{~b}$.

On comparison with literature, the general stress decay trend in Fig 3a is similar, yet there is significant quantitative variation, even between sources. Whilst a proportion of this variation is likely due to differences in microstructure, there are still significant dissimilarities between authors' who have investigated similar initial conditions [4,9]. Various initial pre-strains and strain rates have also been used in the literature, often selected to best replicate the process of interest [13]. This will also invariably affect stress relaxation response. The pre-strain for this study was selected to induce maximal elastic yet minimal plastic strain to replicate the elastic nature of residual stress, with a low strain rate of $10^{-4} \mathrm{~s}^{-1}$ used as this is within the typical range of strain rates experienced during thermo-mechanical processing of Ti-6Al-4V [5].

(a)

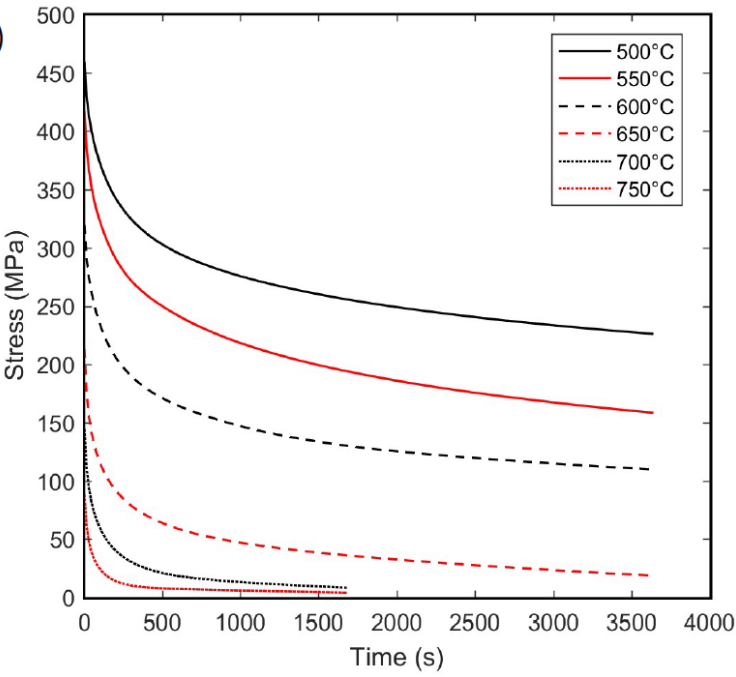

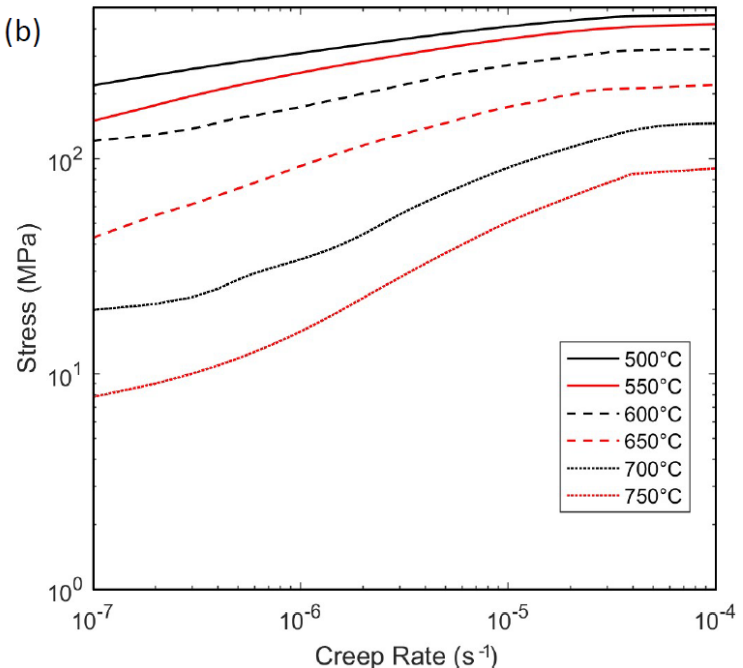

Fig 3: Stress vs. time for temperatures of $500-750^{\circ} \mathrm{C}$ (a), and corresponding plot of stress vs. creep rate (b).

The simulated post-aging residual stress distribution is compared in Fig 4. The residual stress distribution exhibited at all temperatures is typical of quenched material, with high levels of compression near the surface, leading to a region of tension around the centre of the part. A 2-D representation of out-of-plane stress was taken from the mid-plane of the plates. The consideration of creep strain, and thus stress relaxation response, within the simulation is compared at both $500^{\circ} \mathrm{C}$ (Fig $\left.4 \mathrm{a}\right)$ and $750^{\circ} \mathrm{C}$ (Fig 4b). Relatively high magnitudes of residual stress remain within the material after an aging temperature of $500^{\circ} \mathrm{C}$ where there was no consideration of stress relaxation phenomena, with the reduction in residual stress being dependent on plastic relaxation which occurs when the internal residual stress exceeds the temperature dependent flow stress. A maximum tensile stress of $+450 \mathrm{MPa}$, and compressive stress of approximately $-600 \mathrm{MPa}$, was noted for this condition. On comparison with the model 
which considered stress relaxation, the distribution of residual stress follows a similar trend yet with decreased magnitudes, ranging from $+230 \mathrm{MPa}$ to $-320 \mathrm{MPa}$. This is in accordance with the stress decay behaviour noted in Fig. 3a. On consideration of the compressive near surface region, the variation in predicted residual stress between models would have a profound effect on prediction of machining induced deflection which may lead to material wastage and rework. The impact of this is likely to be less important on increasing temperature, as the residual stress tends towards $0 \mathrm{MPa}$ throughout the part (Fig 4c). This is apparent in Fig $4 \mathrm{~b}$ where a maximum and minimum residual stress of +100 and $-105 \mathrm{MPa}$ is noted without consideration of stress relaxation yet almost complete stress relief is recorded where stress relaxation is considered.

Although stress relief is shown to improve on increasing temperature (Fig 4c), there is little improvement between 700 and $750^{\circ} \mathrm{C}$ as the process is effectively complete. Whilst this may appear beneficial in terms of reducing residual stress, aging at such temperatures would lead to thickening of secondary $\alpha$ and in turn, reduced strength [14]. Whilst annealing is commonly conducted in this region, lower temperatures are often selected for aging treatments. As dissolution of brittle $\alpha^{\prime}$ is thought to reach completion at approximately $650^{\circ} \mathrm{C}[15,16]$ and stress relaxation was shown to be most dramatic between $600-650^{\circ} \mathrm{C}$, an aging temperature of $650^{\circ} \mathrm{C}$ may provide an optimal combination of strength, ductility and low residual stress.

Xie et al. [17] conducted post weld heat treatment on Ti-6Al-4V at both $500^{\circ} \mathrm{C}$ and $650^{\circ} \mathrm{C}$ with measurement of residual stress by the contour method both before and after treatment for holding times of 0 to 2 hours. Maximum residual stress was shown to decay over time with a trend similar to that exhibited in Fig 3a, and a maximum of approximately +350 and +70 MPa was noted after 1 hour at 500 and $650^{\circ} \mathrm{C}$, respectively. This compares reasonably well with the maximum stress of $+60 \mathrm{MPa}$ predicted after 1 hour at $650^{\circ} \mathrm{C}$ in this work, yet the maximum at $500^{\circ} \mathrm{C}$ is between the predicted maximum values with and without consideration of relaxation. Although the aforementioned study focussed on welding induced residual stress and the initial microstructure may have differed from that examined in this work, the observed time dependent decay of residual stress supports its use for modelling endeavours.

The simulation did not directly consider metallurgical phenomena such as the $\alpha \leftrightarrow \beta$ and $\beta \rightarrow \alpha^{\prime}$ transformation and as such did not take transformation induced plasticity or transformation induced volume change components of strain into account when computing residual stress. These considerations are more likely to have an effect on quench induced residual stress than on relieving treatments and should be taken into account for accurate through-process prediction of residual stress [18]. However, for the purposes of this study the simplified prediction of quench induced residual stress was deemed acceptable.

Future work to further develop of the model to include metallurgically induced transformations and strains will be carried out. In addition, model validation by means of conducting a prescribed set of heat treatments followed by multi-scale measurement of residual stress using X-ray diffraction, incremental hole drilling and the contour method will allow for a more robust comparison of predicted data [19].

(a) $500^{\circ} \mathrm{C}$

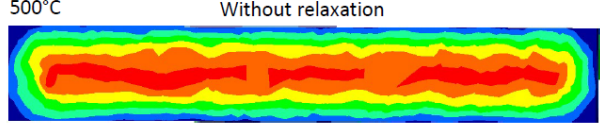

With relaxation

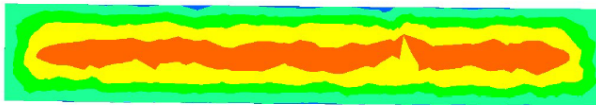

(b) $750^{\circ} \mathrm{C}$

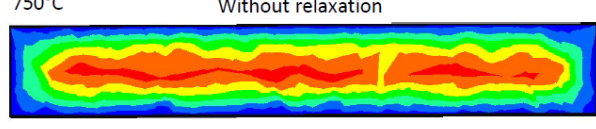

With relaxation

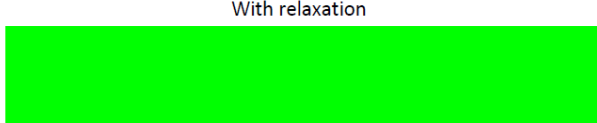

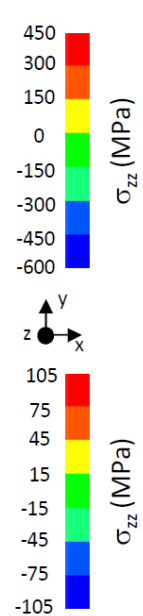

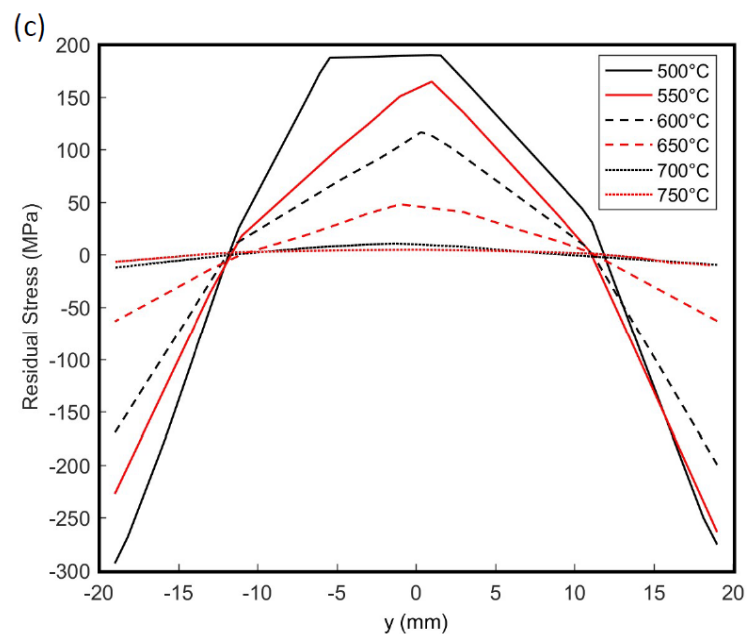

Fig 4: Predicted 2-D out-of-plane residual stress maps taken from the central cross-section of the plate after aging operation showing the variation in predicted stress with and without consideration of stress relaxation phenomena at $500^{\circ} \mathrm{C}(\mathrm{a})$ and $750^{\circ} \mathrm{C}(\mathrm{b})$. $\mathrm{Comparison}$ of predicted through thickness distribution of residual stress for temperatures $500-750^{\circ} \mathrm{C}$ with consideration of stress relaxation phenomena (c).

\section{Conclusions}

Stress relaxation testing was conducted between $500-750^{\circ} \mathrm{C}$ and the resulting behaviour used to provide insight of residual stress evolution during heat treatment within this region. It was found that:

- Stress decay rate was found to increase with temperature. Almost complete relaxation was recorded after 30 minutes for holding temperatures of 700 and $750^{\circ} \mathrm{C}$, compared with a $50 \%$ reduction after 1 hour at $500^{\circ} \mathrm{C}$. 
- The consideration of stress relaxation behaviour had a significant effect on prediction of residual stress. This is more likely to have an adverse effect when simulating aging at low temperatures followed by machining and must be considered appropriately.

- An aging treatment for 1 hour at $650^{\circ} \mathrm{C}$ was predicted to provide a reasonable reduction in residual stress whilst retaining strength and ductility in the final product.

\section{$\underline{\text { Acknowledgements }}$}

This work was supported by Engineering and Physical Sciences Research Council (EPSRC) grant (EP/1015698/1). The authors would like to thank TIMET for the provision of materials, and also Aubert \& Duval for their support on the project. The research was performed at the Advanced Forming Research Centre (AFRC), which receives partial financial support from the UK's High Value Manufacturing Catapult.

\section{$\underline{\text { References }}$}

1. Lütjering G, Williams JC. Titanium. Springer Berlin Heidelberg; 2007. (Engineering Materials and Processes).

2. Withers PJ, Bhadeshia H. Overview - Residual stress part 1 - Measurement techniques. Materials Science and Technology. 2001 Apr;17(4):355-365.

3. Rahimi S, King M, Dumont C. Stress relaxation behaviour in IN718 nickel based superalloy during ageing heat treatments. Materials Science and Engineering: A. 2017 2017/12/21/;708:563-573.

4. Lee T, Kim JH, Semiatin SL, et al. Internal-variable analysis of high-temperature deformation behavior of Ti-6Al4V: A comparative study of the strain-rate-jump and load-relaxation tests. Materials Science and Engineering: A. 2013 2/1/;562:180-189.

5. Rae W. Thermo-metallo-mechanical modelling of heat treatment induced residual stress in Ti-6Al-4V alloy. Materials Science and Technology. 2019 2019/05/03;35(7):747-766.

6. Titanium Metals Corporation. Properties and Processing of TIMETAL ${ }^{\circledR} \quad 6-4.1998$.

7. Denlinger ER, Heigel JC, Michaleris P. Residual stress and distortion modeling of electron beam direct manufacturing Ti-6Al-4V. Proceedings of the Institution of Mechanical Engineers, Part B: Journal of Engineering Manufacture. 2014 2015/10/01;229(10):1803-1813.

8. Bühr C, Ahmad B, Colegrove PA, et al. Prediction of residual stress within linear friction welds using a computationally efficient modelling approach. Materials \& Design. 2018 2018/02/05/;139:222-233.

9. Alabort E, Kontis P, Barba D, et al. On the mechanisms of superplasticity in Ti-6Al-4V. Acta Materialia. 2016 2/15/;105:449-463.

10. Xiao JJ, Li DS, Li XQ. Modeling and Simulation for the Stress Relaxation Behavior of Ti-6Al-4V at Medium Temperature [Article]. Rare Metal Materials and Engineering. 2015 May;44(5):1046-1051.

11. Yan G, Crivoi A, Sun Y, et al. An Arrhenius equation-based model to predict the residual stress relief of post weld heat treatment of Ti-6Al-4V plate. Journal of Manufacturing Processes. 2018 2018/04/01/;32:763-772.

12. Kim JH, Semiatin SL, Lee CS. High-temperature deformation and grain-boundary characteristics of titanium alloys with an equiaxed microstructure. Materials Science and Engineering: A. 2008 6/25/;485(1-2):601-612.

13. Woodford DA. Evolution of a modern mechanical testing and design standard for high temperature materials. Materials Research Innovations. 2016;20(5):379-389.

14. Motyka M, Baran-Sadleja A, Sieniawski J, et al. Decomposition of deformed $\alpha^{\prime}\left(\alpha^{\prime \prime}\right)$ martensitic phase in Ti-6Al-4V alloy. Materials Science and Technology. 2019;35(3):260-272.

15. Salsi E, Chiumenti M, Cervera M. Modeling of Microstructure Evolution of Ti6Al4V for Additive Manufacturing. Metals. 2018;8(8):633.

16. Gil Mur FX, Rodríguez D, Planell JA. Influence of tempering temperature and time on the $\alpha^{\prime}-\mathrm{Ti}-6 \mathrm{Al}-4 \mathrm{~V}$ martensite. Journal of Alloys and Compounds. 1996 1996/02/15/;234(2):287-289.

17. Xie P, Zhao H, Wu B, et al. Evaluation of Residual Stresses Relaxation by Post Weld Heat Treatment Using Contour Method and X-ray Diffraction Method. Experimental Mechanics. 2015 Sep;55(7):1329-1337.

18. Pollard JD, Rahimi S, Watford A, et al. The Determination of Residual Stress in Extruded Ti-6Al-4V by Contour Method and Finite Element Analysis. Proceedings of the 13th World Conference on Titanium: John Wiley \& Sons, Inc.; 
2016. p. 305-310.

19. Rae W, Lomas Z, Jackson M, et al. Measurements of residual stress and microstructural evolution in electron beam welded Ti-6Al-4V using multiple techniques. Materials Characterization. 2017;132:10-19. 